\title{
A Review of the Factors Affecting the Incidence of Malignant Hyperthermia in the Greater Kansas City Area
}

\author{
Charles H. Williams ${ }^{1}$, George P. Hoech ${ }^{2}$, Mark G. Zukaitis ${ }^{3}$ \\ ${ }^{1}$ Sunrise Beach, USA \\ ${ }^{2}$ Kansas City, USA \\ ${ }^{3}$ Gastonia, USA \\ Email: ${ }^{*}$ chwilliams2135@sbcglobal.net
}

Received 25 January 2014; revised 9 March 2014; accepted 26 March 2014

Copyright (C) 2014 by authors and Scientific Research Publishing Inc.

This work is licensed under the Creative Commons Attribution International License (CC BY). http://creativecommons.org/licenses/by/4.0/

(c) (i) Open Access

\begin{abstract}
Malignant Hyperthermia (MH) is a rare genetic disease. However, it is devastating when it occurs in a patient. $\mathrm{MH}$ is usually triggered by inhalational anesthetics and/or depolarizing muscle relaxants. Public awareness of MH has increased with the presentation of an episode on the television program, "House", and the availability of web-based information. For over 20 years, the MH susceptible pig has been used in experiments by our group as an animal model for MH in humans. The incidence of Malignant Hyperthermia in the Greater Kansas City Area has declined dramatically since the introduction of Sevoflurane in 1992 as the anesthetic of choice (over $60 \%$ usage rate) in most surgical procedures. Historically, Malignant Hyperthermia was reported to occur at a rate of 1:50,000 during surgical procedures [1]. In the Greater Kansas City Area, Malignant Hyperthermia $(\mathrm{MH})$ occurred at a rate of 1:53,636 during the 1965-1985 time period, as there were $38 \mathrm{MH}$ cases in 35 patients [2]. During the past ten years (1996-2006), there were only 2 cases of $\mathrm{MH}$, representing an incidence rate of $1: 597,240$. That decrease is an 11.13 fold (or 89\%) decrease which is very significant. Despite the reduced incidence of Malignant Hyperthermia, two recent cases of $\mathrm{MH}$ that result in deaths in Wisconsin and Florida make it imperative that $\mathrm{MH}$ is recognized early and appropriate treatment initiated without delay. We have expanded our analysis of the futile cycle mechanism that underlies the MH syndrome. MH is equivalent to the rapid discharge of a battery by a short circuit.
\end{abstract}

\section{Keywords}

Sevoflurane; Malignant Hyperthermia

\footnotetext{
*Corresponding author.
}

How to cite this paper: Williams, C.H., et al. (2014) A Review of the Factors Affecting the Incidence of Malignant Hyperthermia in the Greater Kansas City Area. Advances in Bioscience and Biotechnology, 5, 452-461. 


\section{Introduction}

Malignant Hyperthermia ( $\mathrm{MH})$ is a rare genetic disease. However, it is devastating when it occurs in a patient. $\mathrm{MH}$ is usually triggered by inhalational anesthetics and/or depolarizing muscle relaxants. Public awareness of $\mathrm{MH}$ has increased with the presentation of an episode on the television program, "House", and the availability of web-based information.

For over 20 years, the MH susceptible pig has been used in experiments by our group as an animal model for $\mathrm{MH}$ in humans.

The incidence of Malignant Hyperthermia in the Greater Kansas City Area has declined dramatically since the introduction of Sevoflurane in 1992 as the anesthetic of choice (over 60\% usage rate) in most surgical procedures. Historically, Malignant Hyperthermia was reported to occur at a rate of 1:50,000 during surgical procedures [2]. In the Greater Kansas City Area, Malignant Hyperthermia (MH) occurred at a rate of 1:53,636 during the 1965-1985 time period, as there were $38 \mathrm{MH}$ cases in 35 patients [3]. During the past ten years (1996-2006), there were only 2 cases of $\mathrm{MH}$, representing an incidence rate of 1:597,240. That decrease is an 11.13 fold (or 89\%) decrease which is very significant.

\section{Background}

In 1984, Charles H. Williams, PhD (CHW) was contacted by Maruishi Pharmaceutical Co., Osaka, Japan, via Biodynamics, East Millstone, NJ, to study a new anesthetic agent that they were interested in developing. Sevoflurane was first synthesized in 1971 by a chemist at Baxter Labs, Chicago, USA [4]. Maruishi Pharm. had recently licensed the use of sevoflurane from Baxter Labs. A detailed and complete study of sevoflurane in 8 Malignant Hyperthermia Susceptible (MHS) pigs and 6 normal pigs was performed by CHW [5] [6]. We studied the onset time (time to induction of anesthesia), blood pressure, heart rate, Electrocardiogram (EKG), cardiac output, central venous pressure, core and rectal temperature, plus a complete blood analysis and blood gases, much as would be done in a modern hospital intensive care unit. We also measured the amount of sevoflurane in the inspired air, the expired air, and also the oxygen and carbon dioxide present in the re breathing circuit [7].

Our conclusion was that sevoflurane was a very good anesthetic agent that had a rapid onset. The pig was anesthetized quickly, and recovered very rapidly when sevoflurane was discontinued which allowed the pig to wake up very quickly. These data were presented at the New York State Anesthesiologists meeting at the Hilton: New York City in October 1989 [6].

Maruishi then developed sevoflurane for the Japanese market and commenced clinical studies in humans. CHW provided a notarized letter that the scientific results reported in 1984 were true science and was not influenced by the paid contract to perform the studies.

In 1990, Maruishi purchased the complete rights to sevoflurane from Baxter Labs for a total of 8 million dollars payable in four payments of two million dollars each year over a four year period [8]. They purchased the patent rights to the one-step synthesis procedure. This outright purchase prevented anyone, including Baxter Labs from making sevoflurane by the one step process and selling it in any market. Subsequently, Maruishi Pharm. entered into an agreement with Abbott Labs, Chicago and Baxter Labs, to have Abbott Labs as the sole distributor of sevoflurane in the USA [8]. A recent court case reveals that sevoflurane brought in 200 million dollars in sales in the USA in 2000 to Abbott Labs. Sevoflurane represents $57.7 \%$ of all anesthetic sales in the USA [8].

As would be expected, Baxter Labs was distressed to discover it had sold the rights to the \#1 anesthetic in the USA. As a competitive strategy, Baxter Labs bought Ohmeda (Ohio Medical), a defunct US anesthesia company, which had developed a 2-step process for making sevoflurane and obtained a patent that would then allow the manufacture of sevoflurane by a 2-step process that did not utilize the 1-step patent process Baxter had sold to Maruishi. In litigation with Maruishi and Abbott, the court ruled that Baxter could not sell their generic version of sevoflurane until December 2005 [8]. Subsequently, several problems have appeared from the use of generic versions of sevoflurane [9].

\section{Data Collection}

Anesthesia data was requested from 22 Hospital and Surgicenters in the Greater Kansas City Area for the year 2006. Five Hospitals did not respond (Table 1 and Figure 1). 
Table 1. Greater Kansas City Area data 2006.

\begin{tabular}{|c|c|c|c|c|c|c|c|}
\hline & All Inhalants & Sevoflurane & $\begin{array}{l}\text { \% Succinyl } \\
\text { choline (SC) }\end{array}$ & $\begin{array}{l}\text { Sevoflurane } \\
\text { plus SC }\end{array}$ & $\begin{array}{l}\text { Other inhalants } \\
\text { plus SC }\end{array}$ & $\begin{array}{l}\text { No. of MH cases } \\
\text { in last } 10 \text { yrs }\end{array}$ & RX Dantrolene \\
\hline 1 & 15,000 & 13,500 & 1.0 & 135 & 15 & 0 & \\
\hline 2 & 3000 & 600 & 20.0 & 120 & 480 & 0 & \\
\hline 3 & 3600 & 1260 & 1.0 & 13 & 23 & 0 & \\
\hline 4 & 7000 & 3500 & 7.5 & 263 & 262 & 0 & \\
\hline 5 & 8400 & 6300 & 10.0 & 630 & 210 & 0 & \\
\hline 6 & 6000 & 4800 & 2.0 & 96 & 24 & 0 & \\
\hline 7 & 6000 & 5400 & 27.0 & 1458 & 168 & 0 & \\
\hline 8 & 2400 & 1800 & 5.0 & 90 & 30 & 0 & \\
\hline 9 & 1500 & 300 & 30.0 & 90 & 360 & 0 & \\
\hline 10 & 5000 & 4000 & 10.0 & 400 & 100 & 0 & \\
\hline 11 & 1800 & 1800 & 19.0 & 350 & 0 & 0 & \\
\hline 12 & 9000 & 900 & 20.0 & 180 & 1620 & 0 & \\
\hline 13 & 4770 & 3577 & 15.0 & 536 & 179 & 0 & \\
\hline 14 & 6898 & 6553 & 35.0 & 2293 & 121 & 0 & \\
\hline I5 & 5525 & 4143 & 55.0 & 2278 & 760 & 0 & \\
\hline 16 & 15,000 & 5250 & 60.0 & 3150 & 5850 & 0 & \\
\hline 17 & 18,555 & 8378 & 19.0 & 1591 & 3525 & 2 & $\begin{array}{c}\text { A c Dantrolene-good } \\
\text { recovery }\end{array}$ \\
\hline Total & 119,448 & 72,061 & Avg \% 20.0 & 13,673 & 13,727 & 2 & \\
\hline \multicolumn{8}{|c|}{ Incidence of MH Cases in KC was one case per 597, 240} \\
\hline
\end{tabular}

Note: Seventeen out of 22 surgical centers/departments in the Greater Kansas City Area responded with data for this study.

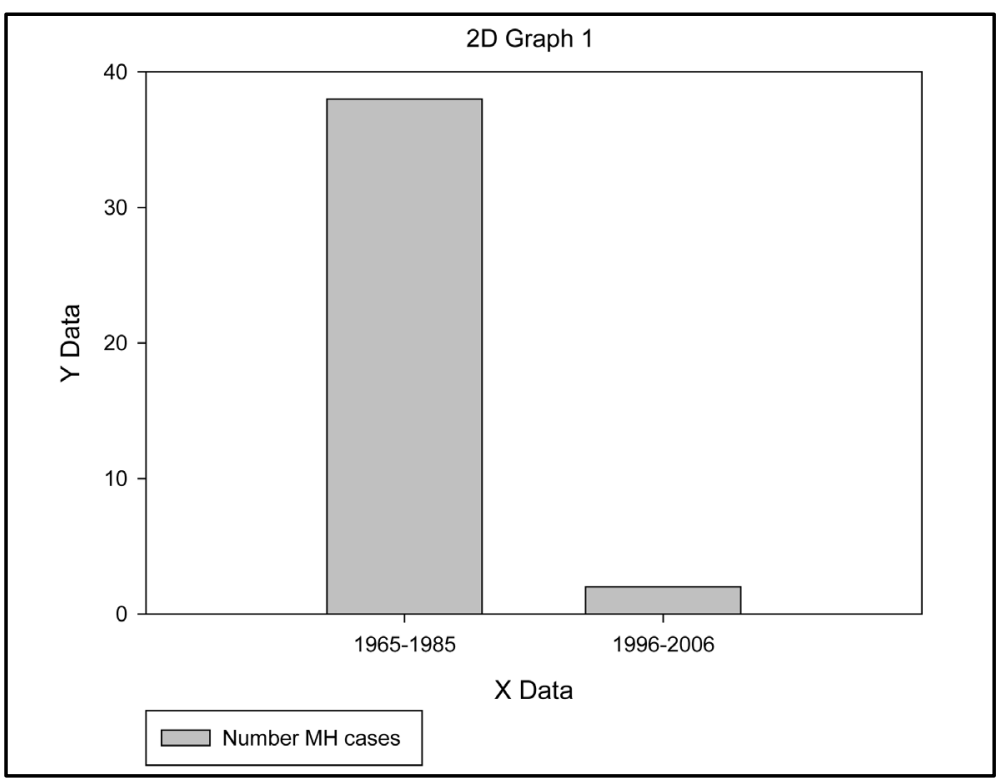

Figure 1. Number of MH cases in the Greater Kansas City Area. 
During 2006, 119,448 general anesthetics were administered in the 17 surgical suites surveyed. The data we obtained were: 1) Total inhalation general anesthetics: $119,448 \times 10$ yrs $=1,194,480.2$ ) $\mathrm{MH}$ incidence: $2: 1,194,480=1: 597,240$. We extrapolated the 2006 number of potent inhalational anesthetics for this period of 10 years which gives a total of 1,194,448 anesthetics. The incidence of MH is 1:597, 240. The two MH cases in the Kansas City area during 1996-2006 were diagnosed early, treated with dantrolene sodium, survived the MH episode, and had a full recovery.

The administration of anesthetics used was: 1) Sevoflurane: 72,061; 2) Sevoflurane + Succinylcholine: 13,673; 3) Percent Sevoflurane + Succinylcholine: 18.9\%; 4) Other Inhalational Agent + Succinylcholine: 13,727.

A total of 72,061 Sevoflurane anesthetics were administered accounting for 60 per cent of the general anesthetics. All other potent inhalation anesthetics totaled 47,387 accounting for the remaining 40 per cent. 19 percent of each group received succinylcholine. We extrapolated the surgical case data back for a period of 10 years to obtain data for the MH cases.

We conducted a MedLine search of the literature on MH cases with Sevoflurane and found 29 reported cases of MH during the use of sevoflurane anesthesia. Succinylcholine was used as the muscle relaxant in all of these MH cases; all patients were treated with Dantrolene and survived.

Outside the Greater Kansas City Area, the MH case of SPN of Lacrosse, WI was brought to our attention [10]. The reporting article did not state whether succinylcholine was utilized and which potent inhalational agent was used. SPN was treated with Dantrolene, but did not survive.

By 1972, CHW had developed the premise that depolarizing muscle relaxants were a primary cause of MH in Malignant Hyperthermia Susceptible (MHS) pigs along with Halothane anesthesia [11]. That premise is illustrated in Figure 2.

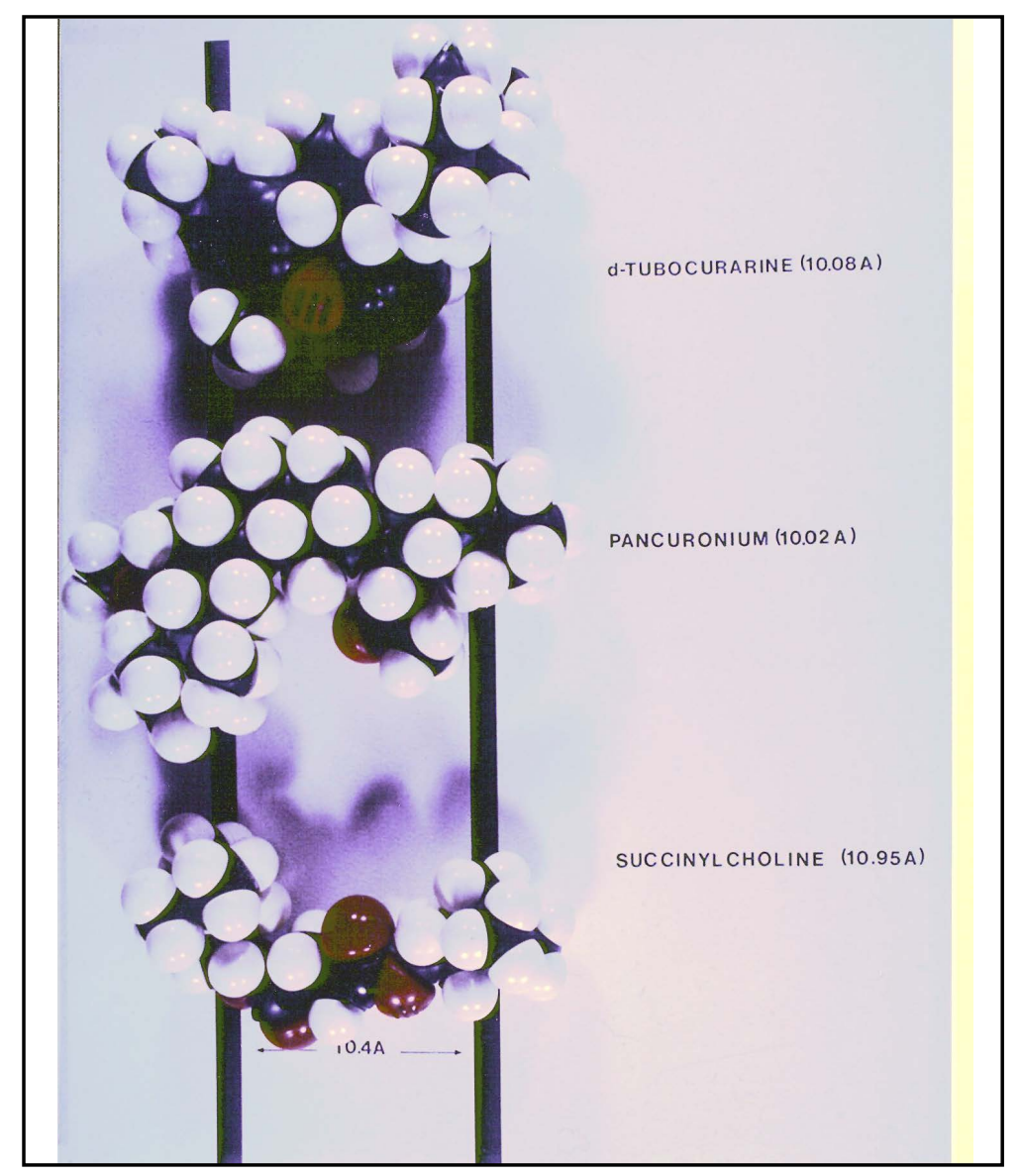

Figure 2. FISHER atomic model of $d$-Tubocurarine, Pancuronium, and Succinylcholine. Note the 10.4 Angstrom spacing of the quaternary ammonium groups which is believed to be necessary for pharmacologic activity. 
Hoech, et al. further developed this premise by using Metubine Iodide to protect the MHS pig from Halothane induced $\mathrm{MH}$ [12]. A pharmacologic dosage was required to achieve this protective effect. Buzello, et al. extended this notion by showing that Vecuronium, a non-depolarizing muscle relaxant was safe to use in MHS pigs [13]. However, a clinical dose of Vecuronium did not protect the MHS pigs from a triggering dose of Halothane. CHW, et al. also showed that Atracurium, another non-depolarizing muscle relaxant did not trigger $\mathrm{MH}$ in MHS pigs [14]. Nor did a clinical dose of Atracurium protect the MHS pigs from a triggering dose of Halothane. Organon 9426 (Rocuronium), another non-depolarizing muscle relaxant, did not trigger MH in MHS pigs [15], but did have the unusual property of completely blocking the development of MH in MHS pigs from use of Halothane at a clinical dosage level [15].

We have developed the idea that a sodium channel genetic defect is the cause of $\mathrm{MH}$. This premise has been presented in a full length publication [1].

\section{Discussion}

Since the introduction of Sevoflurane into clinical anesthesia practice about 1992, there has been an 11.13 fold (or 89\%) decrease in MH cases in the Greater Kansas City Area surgical suites during the 1996-2006 period. We attribute the decrease to four factors: 1 ) use of Sevoflurane as the anesthetic of choice. 2) decline in the use of succinylcholine. 3) diligent intake questioning as to the patient's Family History, Medical History, and physical findings, and if any factor is suggestive of MHS, succinylcholine and potent inhalational agents are customarily avoided; 4) the prophylactic use of Dantrolene in select cases, which has probably prevented clinical MH cases. (The relevant items in the Family History, Medical History, and pertinent physical findings are described in the MHAUS Adverse Metabolic Reaction to Anesthesia Report Form [16].) As a result of these pro-active changes in the practice of anesthesia, there have only been two MH cases in the Greater Kansas City Area during the past 10 years. This contrasts markedly with the thirty-eight MH cases during a 20 year period (1965-1985). If you divide the 38 cases in 20 years (1.9/year) by 2 cases in ten years ( $0.2 /$ year), the incidence of $\mathrm{MH}$ has declined to $11 \%$ of its previous rate of occurrence due to the present procedures, with no fatal incidents.

Our experimental studies of sevoflurane showed that over two hours of sevoflurane anesthesia is required to trigger MH in highly susceptible MHS pigs. The MH syndrome that developed was very mild and easily reversed by dantrolene. All of our experimental MHS pigs were recovered, held for one week to clear all drugs, and rechallenged with Halothane to prove a second time that they were MH susceptible [6].

We believe that the complete elimination of succinylcholine from the surgical suite could further reduce the incidence of $\mathrm{MH}$. All of the reported cases of $\mathrm{MH}$ in human patients were accompanied by succinylcholine usage as the muscle relaxant during sevoflurane anesthesia. Our experimental work with MHS pigs clearly demonstrated that succinylcholine was capable of triggering MH by itself without the use of halothane [11]. We also demonstrated that halothane was capable of triggering MH in MHS pigs. These facts alone strongly suggest that the elimination of these two agents should further decrease the incidence of MH in human patients. Physicians who use these agents are playing a game of chance with their patient's life because sporadic cases escape detection and show up as a fully developed MH case. Physicians who continue to use succinylcholine should complete a critical risk vs. benefit analysis of each patient before using succinylcholine. If succinylcholine is used, the treating physician should be prepared for the possibility of a MH reaction and have appropriate remedial treatments available.

The selective identification and treatment of MHS patients with alternative drugs may have played a role in decreasing the number of MH cases in the Greater Kansas City Area, however, because we do not have a rapid, accurate test for MH susceptibility in human patients that can be applied prior to surgery, there will be MHS patients that slip through the personal history screening process.

We have not observed a large shift in the population of the Greater Kansas City Area that could account for the decreased incidence of MH cases.

Two recent fatal cases of MH in young people, SPN from La Crosse, WI and SJK, [17]-[21] of Boca Raton, FL highlight the fact that $\mathrm{MH}$ in human patients remains a life threatening situation that needs our full attention.

Anesthesia Record SPN, La Crosse, WI dated 12 Jan 2005:

1) Preop Evaluation: The only comment of note was patient's preoperative anxiety.

2) Pulse: Initial pulse rate on anesthesia record was $82 / \mathrm{min}$. After 1400 hrs. the pulse rate rose gradually to 120/min. at 1625 hours. The last recorded pulse rate on the record was 132/min. at 1625 hours. Labetelol $5 \mathrm{mg}$. 
at $1304 \mathrm{hrs}$. and $7.5 \mathrm{mg}$. at $1430 \mathrm{hrs}$. was given to decrease BP and caused slight decreases in pulse rate.

3) End Tidal $\mathrm{CO}_{2}$ rose from 48 Torr at 1200 hrs. After two hours of anesthesia $\mathrm{ETCO}_{2}$ was in mid 50s and after four hours in upper 60s. At 4 hrs. 15 min. ETCO $_{2}$ was 80 Torr, at 4 hrs. $30 \mathrm{~min}$. $\mathrm{ETCO}_{2}$ was 110 Torr.

4) Airway: Anesthesia was administered via a LMA (Laryngeal Mask Airway). It is not evident whether respirations were controlled, spontaneous or assisted. I could not determine respiratory rate, Tidal volume or minute volume.

5) Temperature was monitored via axillary temperature probe. Temperature started at $32^{\circ} \mathrm{C}$ and in the first hour rose to $34^{\circ} \mathrm{C}$, rising to $36^{\circ} \mathrm{C}$ at 1600 hours (I could find no record of the core temperature being measured.).

6) Timeliness of MH diagnosis: The presumed triggering agent Sevoflurane was discontinued at 1629 hours. MH cart was brought to operating room at the same 1629 hours. The warming blanket was turned off at 1540 hours. There was not a timely diagnosis of the MH metabolic process.

Unfortunately, SPN died after several hours of resuscitative treatment. (Drs. Henry Rosenberg and Al Rothstein stated in the APSF Newsletter Summer 2006 Vol. 21, No.1, p. 32 regarding this patient: "By the time the anesthesia team determined that MH was occurring and Dantrolene should be given, the train had left the station and was racing down the tracks.”)

The temperature monitoring via axillary (armpit) did not provide an accurate and reliable temperature readout of core or rectal temperature. We have published data from our MHS pig experiments showing that the skin ceases to radiate heat whenever MH develops [22]. The heat produced in MH comes from muscle mass so temperature monitoring must be internal rather than external [23]. This observation is further supported by the fact that esophageal temperature was $110.8^{\circ} \mathrm{F}$ after the patient was intubated with a \# 8 O.T in the SPN case (Figure 3).

SJK, case number: 08-0366, West Palm Beach, FL. [18] "[SJK] was given succinylcholine, she developed muscle rigidity and her body temperature rose. She was transferred to the nearest emergency department. She developed disseminated intravascular coagulation and multi-organ failure and died at the hospital.”

\section{Conclusions}

The Malignant Hyperthermia Susceptible pig has been a superb animal model for human Malignant Hyperthermia. See CHW's extensive publications on this subject [23]-[28]. Given that extensive human testing of the MH response is not possible, the animal model remains the best tool for evaluating the suitability of various anesthetic treatments of human patients. The available data suggest that MH human patients have the same negative response to succinylcholine and halothane as the animal model.

We now have a well tested anesthetic, Sevoflurane, which has been used for many years in millions of people that is a weak trigger for Malignant Hyperthermia. This is borne out by only $29 \mathrm{MH}$ cases in the literature and a 19 fold (or 89\%) decrease of MH incidents in the Greater Kansas City Area.

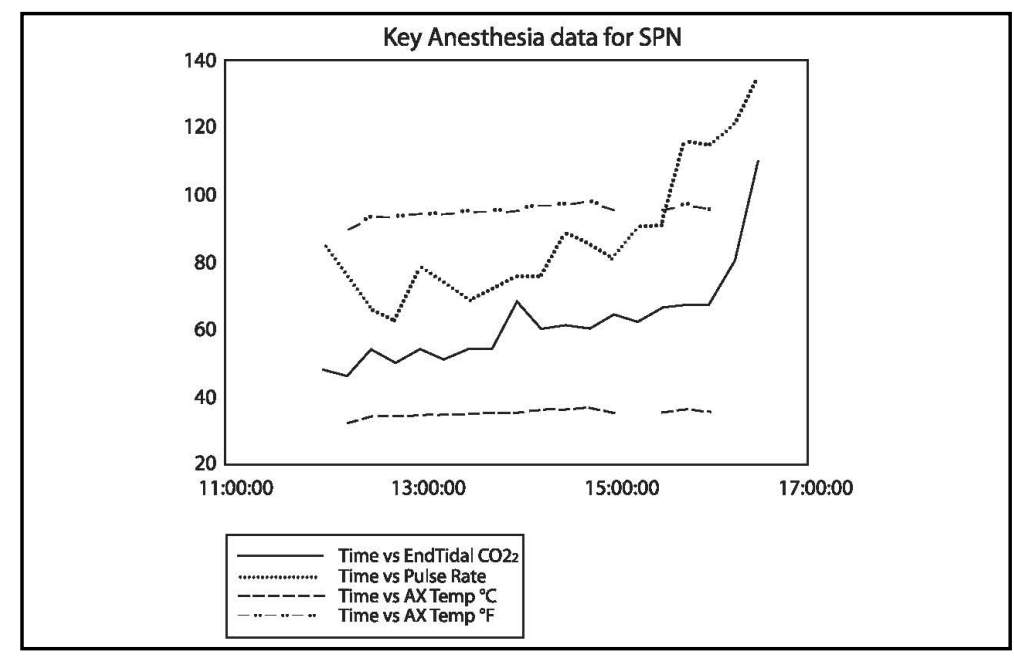

Figure 3. Key Anesthesia data for SPN. Data were obtained from the anesthesia record of SPN. 
We have three muscle relaxants, Vecuronium, Atracurium, and ORGANON 9426 (Rocuronium) that are known to be non triggering agents in the MHS pig and the available data suggest that they are safe to use in humans. Rocuronium is the only muscle relaxant that can also prevent $\mathrm{MH}$ in pigs when challenged with Halothane or succinylcholine.

\section{Futile Cycle Analysis}

The rapid rate of heat production in muscle is driven by a futile cycle, most likely by a rapid membrane depolarization of the $90 \mathrm{mv}$ membrane potential, by a defective sodium channel. The genetically defective sodium channel is evidenced by an action potential at the myoneural junction that is higher in amplitude and of longer duration than a normal action potential [29]. This electrical activity is equivalent to a short circuit in a battery that produces copious amounts of heat and thereby drives the metabolism to a maximum rate of over $10 \times$ normal.

\section{Acknowledgements}

Note: This manuscript was presented at the Amer Physiol Soc Fall meeting at Hilton Head, SC as 20.3 on board \# 67 on 26 Sept 2008. The abstract is in The Physiologist: 51(6): 54, Dec 2008.

The graphs were prepared with Sigma Plot v.11 and translated by Advantage Systems Inc., Camdenton, MO to the current format.

We thank Kate Andersen, University of Missouri Medical School Library, Columbia, MO for the computer search online for the Malignant Hyperthermia-Sevoflurane published works.

We thank Gregory D. Williams, JD and Nathan C. Williams, JD for editorial revision of this manuscript.

We thank Dolores B. Williams, BS for typing and revising the manuscript.

\section{References}

[1] Williams, C.H. (2014) Malignant Hyperthermia: A Runaway Thermogenic Futile Cycle at the Sodium Channel Level. Advances Bioscience Biotechnology, 5, 197-200. http://dx.doi.org/10.4236/abb.2014.53025

[2] Britt, B.A. (1987) A History of Malignant Hyperthermia. In: Malignant, H., Ed., BA Britt, Martinus Nijhoff Publishing, Boston, xi-xxii.

[3] Zukaitis, M.G., Hoech, Jr., G.P. and Robinson, J.D. (1986) Malignant Hyperthermia—Pre and Post Dantrolene: A Survey of the Greater Kansas City Area from 1965-1985: 15 Sept 1965. January 1986 Meeting of the Rocky Mountain Traumatoligic Society in Aspen,

[4] Wallin, R.F. and Napoli, M.D. (1971) Sevoflurane (Fluro-methyl-1,1,1,3,3,3,-hexafluro-2-propyl ether) a New Inhalational Agent. Fed Proceed, 30, 442.

[5] Williams, C.H., et al. (1989) Cardiac Performance and Hemodynamics in Malignant Hyperthermia Susceptible and Normal Pigs during Sevoflurane Anesthesia. Attachment \#1.

[6] Williams, C.H., Stovall, R.M., Dozier, S.E., Watts, M.T., Bayless, P.A., Marvasti, M.A., Farias, M., Ekery, D.D., Daley, I.W. and Satoh, N. (1988) Cardiac Performance and Hemodynamics in Malignant Hyperthermia Susceptible and Normal Pigs during Sevoflurane Anesthesia. Poster Presentation at the New York State Society of Anesthesiologists Meeting, Hilton, New York City, 10 December 1989,

[7] Watts, M.T., Escarzaga, M. and Williams, C.H. (1992) GTas-Chromatographic Headspace Analysis of Sevoflurane. Journal of Chromatography B: Biomedical Sciences and Applications, 577, 289-298. http://dx.doi.org/10.1016/0378-4347(92)80250-T

[8] Abbott Laboratories v. Baxter International Inc. (2002) WL 467147 (N.D.Ill. 2002).

[9] Kharasch, E.D. (2007) Sevoflurane: The Challenges of Safe Formulation. APSF Newsletter Fall, 22, 48.

[10] Rosenberg, H. and Rothstein, A. (2006) Malignant Hyperthermia Death Holds Many Lessons. APSF Newsletter: Summer, 21, 32-34.

[11] Williams, C.H., et al. (1977) Proceedings of the Focus on Malignant Hyperthermia Symposium, Wausau, 13 September, 3 Chapters. EO Henschel, Appleton Century Crofts, New York.

[12] Hoech, Jr., G.P., Roberts, J.T., Williams, C.H., Waldman, S.D., Simpson, S.T. and Trim, C.M. (1980) Prevention of Porcine Malignant Hyperthermia with Metocurine. In: Thermoregulatory Mechanisms and Their Therapeutic Implications. 4th International Symposium Pharmacology of Thermoregulation, Oxford, 137-141, Karger:Basel.

[13] Buzello, W., Williams, C.H., Chandra, P., Watkins, M.L. and Dozier, S.E. (1985) Vecuronium and Porcine Malignant 
Hyperthermia. Anesthesia \& Analgesia, 64, 575-279. http://dx.doi.org/10.1213/00000539-198505000-00012

[14] Williams, C.H., Dozier, S.E., Ilias, W.K. and Fulfer, R.T. (1985) Porcine Malignant Hyperthermia: Testing of Atracurium in MH Susceptible Pigs. Anesthesia \& Analgesia, 64, 112.

[15] Williams, C.H., Chandra, P., Serda, R. and Martinez, M. (1992) Malignant Hyperthermia Induction in Susceptible Swine Following Exposure to Organon 9426. Abstracts S350. Anesthesia \& Analgesia, 74, S1-S365.

[16] (2006) MHAUS AMRA Report Version 9.1.

[17] (2008) Milwaukee Journal Sentinel: JS Online: Only 20, Athlete Had Zest for Life (Steven Nook). By Amy Rabideau Silvers.

[18] Stephanie Kuleba, Case \# 080366, Palm Beach Medical Examiner’s Office.

[19] (2008) The Informed Patient: A Fresh Focus on a Rare Risk of Anesthesia. The Wall Street Journal: 4/30/2008, Laura Landro.

[20] Medical Examiner’s Office (2008) West Palm Beach, Stephanie J. Kulebea, Case \# 080366:21 May 2008.

[21] (2008) Making Everlasting Memories, Worldwide Memoralization—Stephanie Jude Kuleba: Guest Book: 10/24/2008.

[22] Williams, C.H., Houchins, C. and Shanklin, M.D. (1975) Energy Metabolism in Pigs Susceptible to the Fulminant Hyperthermia-Stress Syndrome. British Medical Journal, 3, 411-413, Errata 604.

[23] Cark, M.G., Williams, C.H., Pfeifer, W.F., Bloxham, D.P., Holland, P.C., Taylor, C.A. and Lardy, H.A. (1973) Accelerated Substrate Cycling of Fructose-6-Phosphate in the Muscle of Malignant Hyperthermic Pigs. Nature, 245, 99-101. http://dx.doi.org/10.1038/245099a0

[24] Williams, C.H. (1974) The Development of an Animal Model for the Fulminant Hyperthermia-Porcine Stress Syndrome. Proceedings of the Focus on Malignant Hyperthermia Symposium, Wausau, 13 September 1974, 117-140.

[25] Williams, C.H., et al. (1977) The Fulminant Hyperthermia-Stress Syndrome: Genetic Aspects, Hemodynamic and Metabolic Measurements in Susceptible and Normal Pigs. Proceedings of 2nd International Symposium on Malignant Hyperthermia, Denver, 1-3 April 1977, 161-173.

[26] Williams, C.H., Farias, M., Marvasti, M.A., Knight, A.B., Ekery, D.D., Daley, I.W. and Zayed, I. (1990) Malignant Hyperthermia Induction in Susceptible Swine Following Exposure to Arduan. Anesthesia \& Analgesia, 70, S433. http://dx.doi.org/10.1213/00000539-199002001-00433

[27] Williams, C.H., et al. (1986) Metabolic Rate in Malignant Hyperthermia Pigs. In: Swine in Biomedical Research, Vol. 1, Ed., ME Tumbleson, Plenum, New York, 573-582.

[28] Williams, C.H. (1988) Experimental Malignant Hyperthermia. Springer Verlag, New York.

[29] Steiss, J.E., Bowen, J.M. and Williams, C.H. (1981) Electromyographic Evaluation of Malignant Hypermia Susceptible Pigs. American Journal of Veterinary Research, 42, 1175-1178. 


\section{Attachments}

Sevoflurane abstract: Williams, CH et al. 1985 submitted to IARS, 27 July 1989. However, it was rejected for presentation at the Fall 1989 meeting.

Title: CARDIAC PERFORMANCE AND HEMODYNAMICS IN MALIGNANT HYPERTHERMIA SUSCEPTIBLE AND NORMAL PIGS DURING SEVOFLURANE ANESTHESIA

Authors: C.H. Williams, Ph.D., R.M. Stovall, M.D., S.E. Dozier, B.S., M.T. Watts, Ph.D., P.A. Bayless, M.D., M.A. Marvasti M.D.,

Affiliation: Tas Tech Univ. HSC-RAHC, El Paso, TX 7990s

\begin{abstract}
Introduction: Sevoflurane (fluoromethyl-1,1,1,3,3,3 hexafluro-2-propyl ether) was reported by Wallin and Napol (1971) as a new anesthetic agent. We have conducted an extensive study of sevoflurane(SF) anesthesia effects on cardiac performance, hemodynamics and $\mathrm{MH}$ triggering potential in MHS and normal pigs.

Methods and Materials: An Ohio model 2000 anesthesia machine @ 5L/min/ $\mathrm{O}_{2}$ flow was calibrated for sevoflurane usage. Samples were analyzed for SF concentration by injection into a Varian Series 2100 gas chromatograph. Four different groups of animals were used: six MHS pigs at maximum tolerable dose (MTD) at $3.5 \%$ inhaled SF, six control \#1 pigs at $2 \%$ SF for 2 hrs, three MHS pigs (three survivors from group \#1) exposed to $2 \%$ halothane for comparative data, six control \#2 pigs exposed to $2 \% \mathrm{SF}$ for 1 $\mathrm{hr}$ and then further exposed to $3.5 \%$ SF (MTD) for 1 additional $2 \mathrm{hr}$ period. The animals were premedicated with thiopental $(22 \mathrm{mg} / \mathrm{kg})$, intubated, and mechanically ventilated with $33 \% \mathrm{O}_{2}: 67 \% \mathrm{~N}_{2} \mathrm{O}$. Invasive monitoring consisted of venous $\mathrm{O}_{2}$ sat., CVP, PAP, PAPw, cardiac output, arterial $\mathrm{O}_{2}$ sat., arterial pressure, left ventricular $\mathrm{dP} / \mathrm{dT}$, ECG, core and temperature, complete blood gases and core and rectal TTUHSC ACUC assigned protocol \#86099-1. Statistic analyses were run on a PC's Limited $286^{\circ}$ computer using SPSS PC+. The MHS pigs (inbred) were from our MHS colony and averaged $126.58 \mathrm{\#} \mathrm{BW.} \mathrm{Control} \mathrm{pigs} \mathrm{were}$ purchased from Paso Pork. Control \#1 pigs averaged $58.03 \#$ $\mathrm{BW}$ and control \#2 pigs averaged $120.45 \# \mathrm{BW}$. After invasive lines were inserted, each pig was cooled to a core temperature of $37-38^{\circ} \mathrm{C}$. SF dosage was given at the maximum tolerable dose $(3.5 \%)$ with continuous monitoring until Malignant Hyperthermia developed.

Results: From the tabulated data, eleven derived variables were calculated. They were: $m$ AP, mPAP, CI SV variables PVR, TPR, RVSWI, LVSWI and CPP. Blood SF levels reached $0.35 \mathrm{mM}$ at 60 minutes of exposure in control $\# 1$ pigs exposed to $2 \% \mathrm{SF}$ and stayed at that level. Blood $\mathrm{SF}$ levels reached $0.55 \mathrm{mM}$ at 60 minutes of exposure in MHS pigs exposed to $3.5 \% \mathrm{SF}$ and increased up to $0.64 \mathrm{mM}$ at two hours of exposure. Blood SF levels reached $0.378 \mathrm{mM}$ at 60 minutes of exposure to $2 \%$ inhaled SF in control \#2 pigs and reached $0.681 \mathrm{mM}$ after exposure to $3.5 \%$ inhaled SF for two hours. Core temperature decreased significantly $(P<0.05)$ at ten minutes in MHS pigs under SF anesthesia. A significant $(P<0.05)$ decrease in core temperature was also noted in control \#1 pigs at 20 minutes of SF exposure. End tidal $\mathrm{CO}_{2}$ significantly decreased $(P<0.05)$ in MHS and the control \#1 group of pigs at 10 minutes after exposure to SF. The MHS group of pigs showed a significant increase $(P<0.05)$ of tidal $\mathrm{CO}_{2}$ at 120 minutes which was consistent with the beginning stages of $M H$ development. Heart rate significantly decreased in control \#1 pigs at 10 minutes $(P<0.05)$ exposed to $2 \%$ SF and in MHS pigs after 30 minutes of exposure to $\mathrm{SF}$. At 30 minutes of exposure to $\mathrm{SF}$ all three treatment groups (MHS, Control \#1, Control $\# 2$ ) all three treatment decrease in heart rate which continued to he dad a significant 120 minutes except for the increase in to be depressed up to (tachycardia) at 120 minutes which in MHS pigs heart rate development of MH. Exposure to $2 \%$ SF reduced theginning arterial pressure in all groups but exposure to cause a significant effect $(P<0.05)$. $2 \%$ SF
significantly decreased $(P<0.01)$ the RPP of
\end{abstract}

control \#1 pigs at 10 minutes of exposure. At 50 minutes SF caused a significant decrease $(P<0.05)$ in the cardiac output of MHS pigs. This decreased cardiac output continued up thru 90 minutes and then cardiac output increased in response to the developing $\mathrm{MH}$ syndrome concomitant with catecholamine release. There was a significant $(P<0.01)$ catecholamine release. There was a significant $(P<0.01)$
reduction in coronary perfusion pressure (CPP) at 40 thru 120 reduction in coronary perfusion pressure (CPP) at 40 thru 120
minutes in MHS pigs. Both groups of control pigs had a minutes in MHS pigs. Both groups of control pigs had a
higher cardiac index than the MHS pigs with the control \#2 group at $130.25 \mathrm{ml} / \mathrm{min} / \mathrm{Kg}$ being significantly higher $(P<0.05)$ than the $86.23 \mathrm{ml} / \mathrm{min} / \mathrm{Kg}$ of MHS pigs at zero time. SF exposure significantly decreased the CI of MHS pigs at 40 minutes $(P<0.01)$ thru 90 minutes. The stroke volume (SV) of MHS pigs was $38.85 \mathrm{ml} /$ beat at zero time compared to control \#2 pigs had $60.76 \mathrm{ml} /$ beat at zero time. Stroke volume in MHS pigs increased significantly $(P<0.01)$ up to $44.2 \mathrm{ml} /$ beat at 20 minutes exposure to sevoflurane. There was a dramatic difference between the stroke volume index in normal pigs $(1.1 \mathrm{ml} / \mathrm{beat} / \mathrm{Kg})$ versus the significantly decreased stroke volume index of MHS pig at $0.7 \mathrm{ml} / \mathrm{beat} / \mathrm{Kg}$ during the control period and during SF administration. The MHS pigs are only pumping $63.5 \%$ of the blood volume to peripheral tissues as occurs in normal pigs. The control \#2 pigs had a significantly $(P<0.01)$ higher LVSWI at $1.625 \mathrm{~g}$ $\mathrm{m} / \mathrm{Kg} /$ beat than MHS pigs at $0.77 \mathrm{~g}-\mathrm{m} / \mathrm{Kg} /$ beat. The control $\# 1$ and halothane pigs had intermediate values at $1.023 \mathrm{~g}$ -
$\mathrm{m} / \mathrm{Kg} / \mathrm{beat}$ and $1.12 \mathrm{~g}-\mathrm{m} / \mathrm{Kg} / \mathrm{beat}$ respectively. The MHS pigs had a significantly $(P<0.05)$ higher rate at 3613.33 torr/sec as compared to the $2606.66 \mathrm{torr} / \mathrm{sec}$ for control \#1 and 2764.33 torr $/ \mathrm{sec}$ for control \#2 pigs. SF significantly $(P<0.01)$ depressed the LVdP/dT at 40 thru 90 minutes Total peripheral resistance of the control \#1 pigs minutes. dyne-sec/cm as compared to 1495 dyne-sec/ $/ \mathrm{cm}^{5}$ for MUS pigs $(P<0.05)$ Discussion: SF at $(2 \%)$ in control pigs has a primary effect to heart rate, stroke volume, or $\mathrm{dP} / \mathrm{dT}$. Our data in normal pigs suggests that SF would be a useful general anesthetic in surgical cases where lowered blood pressure would be beneficial. SF depressed the heart rate significantly in MHS pigs but did not produce dysrhythmias. This result is in ptriking ond produce dysrhythmias. This result is in depressed premased heart rate with dysrhythmias evidenced by premature ventricular contractions (PVC's). SF will must be in statement must be qualified since it requires two hours or more of SF exposure to trigger $\mathrm{MH}$ in very highly susceptible inbred $\mathrm{MH}$ pigs.

References:

Wallin RF, Napoli MD (1971) Sevoffurane fluro-methyl-1,1,1,3,3,--hexafluro-2-propyl ether) a new inhalational anesthetic agent. Fed Proceed 30:442

2. Shulman M, Braveman B, Ivankovich AD, Groner G (1981) Sevoflurane triggers malignant hyperthermia in swine. Anesthesiology 54:259-260

3. Gronert GA, Milde JH (1981) Variations in onset of porcine malignant hyperthermia Anesth Analg 60:499-503

4. Buzello W, Williams CH, Chandra P, Watkins ML, Dorier SE (1985) Vecuronium and porcine malignant hyperthermia. Anesth Analg 64:515-519

5. Williams CH (1988) Experimental Malignant Hyperthermia, Springer-Verlag, NY.

Acknowledgement: Supported in part by Ancsthesia Associates of Kansas City, MO for the MH pig colony, Biodynamics, Inc., East Millstone, NJ via Project \#84-2900, and Oximetrix 
Title:

Authors:

Affitiation:

THE CARDIOVASCULAR PERFORMANCE OF NORMAL AND MAL IGNANT HYPERTHERMIA SUSCEPTIBLE (MHS) PIGS
DURING SEVOFLURANE ANESTHESIA

S.E. Dozier, B.S., M. Farias, M.T. M.D. M. M.T. Watls, Ph.D.*, P.A. Bayless, M.D.kx,

Medicinekz. Texas Tech Univergity health Sciencesogy, Surgeryax, and Internat

MhS Letreduction. Twelve normal pigs and eight Mhs pigs were exposed to Sevoflurane (fluor ome thy $1-1-1$, $1,1,3,3,3,-$ hexafluoro-2propyl ether) via closed anesthesia in oxygen to determine the cardiovascular effects and to estimate the MH triggering potential.

Metheds. Six normal pigs were exposed to $2 \%$ and $3.5 \%$ Sevoflurane, six normal pios were exposed to $2 \%$ sevoflurane, and eight MHS pigs were exposed to $2 \%$ to $3.5 \%$ Sevoflurane during a 2 hour exposure period. Rnesthesia was induced by ip iniection of $22 \mathrm{mg} / \mathrm{kg}$ of Pentothal. Culdowns were completed to install the Millar Mikro-tip catheter pressure transducer in the left ventricle. The oximetrix Opticath catheter was inserted. in the pulmonary artery and the arterial opticath catheter into the carotio artery alongside the Millar catheter. Cardia outputs were determined with the Edwards computer model 9520 . Data was recorded on an 8 channel HP recordef. End tidal $\mathrm{CO}^{2}$ was measured with a Cavitron analyzer. An Onio model 2000 anesthesia machine with vernitrol was used to delivei the sevoflurane. Gas chromatographio analysis of sevoflurane $(80 / 100$ poropak s columa with flame ionization celection) was 5 column calibrate the anesthesis machin was used to sevoflurane levels in expired air. to measure vapor from blood specimens. All animals were cooled to $37-38$ C before starting were experimental procedures starting the parameters were monitored and recorded: CVP. PAP, Co, monitored and recorded: AP. temperature ETCO2. emperature, PAPw. rectal continuouserterial, Teft ventricular $\sigma P / \sigma T$. mixed venous blood gases, venous terial and expired sevollurane, blood sevous lactate, heart rate. Statistical analyses were performed with student's t-test.

Results. The data shows that core temperature oecreased significantly ( $P(0.05)$ a fiter 40 minutes of Sevoflurane exposure Heart rate decreased signilicantly from $146 \mathrm{bpm}$ down to 1035 bpm sevollurane exposure. Expir 30 minutes 01 remaired stable during. Expired $\mathrm{CO} 2$ values Cardtac index oxposure $\mathrm{mi} / \mathrm{min} / \mathrm{kg}$ down during sevoflurane $67.4 \mathrm{~m} / \mathrm{min} / \mathrm{kg}$ ( $P$ ( 0.05 ) desistance dyne-sec 5 cocreased significantly from 1497. dyne-sec/cms down to 896.3 dyne-sec/cm5 (f exposure. The lef siguichal slrake work index was decreased g-m/kg sevofturat (peres sevorlurane exposure. Coronary perfusion pressure (CPP) decreased steadily throughout the sevoflurane exposure especially as the level approached $3.5 \%$ sevollurane. At 40 minutes the decrease in CPP was significant from 73.66 tort down to 42.0 torr $(P(0.01)$. Rate pressure product decreased significantly ( $P(0.05)$ after a minutes of sevoflurane exposure. We achieved a blood level of $0.7 \mathrm{~mm}$ Sevoflurane with the sevoflurane exposure at $3.5 \%$ for 2.5 to 3.0

Discussion. The decrease in op/at suggests that Sevoflurane has a direct effect on cardiac muscle to occrease contractility. The cardiovascular system was very slable during Sevorturane anesthesia without dysinythmias or ap tor lor , and blood pressure as would be expecteo for many general halogenated anesthetics; however. Sevollurane dio not cause cardiac dysthythmias when given at high doses. The cardiovascular system continued to function smoothly even though it was in a depressed state. our data in normal pigs suggests that sevoliviane would be a useful general anesthetic that could be used in surgical cases where lowered blood pressure would be beneficial.

Sevollutane is a weak trigger for MH and required two to twelve percent hours of exposure to cause Mh to bevelop.

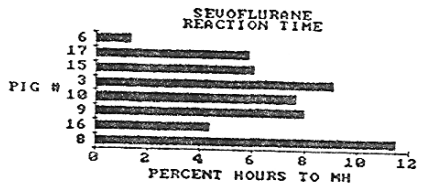

Sevollurane is a better anesthetic than halothane in normal and MHS pigs since it does not sensitize the myocardium and cause dysrhythmias.

Supported in part by: Blodynamics lnc.. Mariushi fharmaceutical Corporation, and texas Tech Seed Grant 6807-78-4220.

\section{References.}

Wallin RF and Napoli MD. Federation Proceedings $30: 442$, 1971

Wallia et 21 . Anesthesia \& Analgesia 54(6):

Holaday DA and Smith FR. Anesthesiology

Apui 2,1987- t. ASA- 